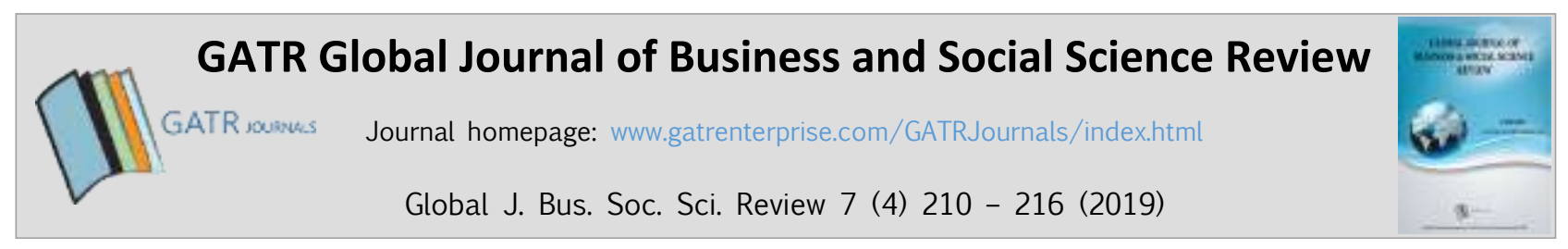

\title{
The Effect of Inquiry-Based Science Comics on Primary Learners' Scientific Literacy Skills
}

\author{
Muhammad Randy Fananta ${ }^{1 *}$, Tria Umbara ${ }^{2}$, Nena P Valdez ${ }^{3}$ \\ ${ }^{12}$ PT Kuark Internasional, Komplek Perkantoran Permata Hijau, 12210, Jakarta, Indonesia \\ ${ }^{3}$ Universiti Teknologi Brunei, Tungku Link Gadong, BE1410, Brunei, Brunei Darussalam
}

\begin{abstract}
Objective - The fundamental scientific literacy skills of primary learners remains crucial as the STEM and Industry 4.0 thrusts begin to configurate across levels. Espousing the view that a visual fun-laden learning medium fosters learners' understanding on natural phenomena and its scientific literacy, this research aims to examine the effect of inquiry-based science comics as a learning medium in improving primary learners' scientific literacy skills.

Methodology/Technique - This study employs the quasi-experimental method, specifically, the pre-test/post-test control group design. Three levels of learners' scientific literacy which covers scientific concepts and phenomena (LTC-1), thinking (LTC-2), and scientific inquiry processes (LTC-3) were quantitatively measured by using problemset tests. The inquiry sequences of observing, questioning, exploring, discussing and evaluating were integral features of the inquiry-based comics and provided the direction of the learning sessions. Improvements in the learners' scientific literacy skills were qualitatively triangulated through series of class observations, learners' experiments and related artefacts, and post-mortem group discussion.

Finding - The results show that there was a significant difference in students' scientific literacy using the inquiry-based comic. The increase in gained score occurred in the first (LTC-1) and second (LTC-2) level of scientific literacy. The skills of making diagrams, charting data and drawing conclusions also progressed in the experimental group. This finding indicates that inquiry-based science comics provide a support platform in developing the fundamental scientific literacy skills of primary graders.

Novelty - The results of this study contribute to the limited literature on the use of instructional inquiry-based science comics in order to leverage scientific literacy skills of primary years.
\end{abstract}

Type of Paper: Empirical.

Keywords: Comic Books; Science; Inquiry-based Comics; Scientific Literacy; Inquiry.

Reference to this paper should be made as follows: Fananta, M. R; Umbara, T; Valdez, N. P. (2019). The Effect of Inquiry-Based Science Comics on Primary Learners' Scientific Literacy Skills, Global J. Bus. Soc. Sci. Review 7(4): 210 - 216. https://doi.org/10.35609/gjbssr.2019.7.4(1)

JEL Classification: I21, I29.

\section{Introduction}

Central to the 21st century global educational initiatives and reforms is ensuring that learners are wellprepared and suitably qualified to engage in STEM career.

\footnotetext{
* Paper Info: Revised: September 13, 2019

Accepted: December 31, 2019

* Corresponding author: Muhammad Randy Fananta

E-mail: randy.fananta@komikuark.net
} 
Affiliation: PT Kuark Internasional, Komplek Perkantoran Permata Hijau, 12210, Jakarta, Indonesia

The relationship between sciences and technology or other knowledge cannot be separated in the discipline of science. There is a strong positive correlation between scientific literacy and inquiry-based learning in STEM education (Yuliati, Yogismawati \& Nisa, 2018). Grounding current practices that support inquiry-approached learning across various levels demands an optimal display of scientific literacy (Riga, Winterbottom, Harris, \& Newby, 2017). Engaging learners to authentic and meaningful activities and allowing them to connect gained learnings with the real world requires contextual processes in aid of learners' acquisition and transfer of scientific-related competencies.

Scientific literacy refers to the knowledge and understanding of scientific concepts and vocabulary, and processes of inquiry required in everyday life for personal decision making, participation in civic and cultural affairs and economic productivity (National Research Council, 1996; Norris \& Phillips, 2003; Wallace, 2004). Scientific literacy can also be defined as the ability of students to relate evidence or data to claims or conclusions involving the processing of scientifically investigable questions, identifying evidence needed in a scientific investigation, drawing or evaluating conclusions and communicating valid conclusion in appropriate ways (OECD, 2000). Hence, OECD (2015) characterizes the scientifically literate person as having these three competencies: (1) explain phenomena scientifically; (2) evaluate and design scientific enquiry; and (3) interpret evidence and data scientifically.

Thus operationally, scientific literacy in this paper encompasses three key ideas/dimensions, namely: Basic Scientific Literacy (LTC-1), the first (basic) level, referring to the practical scientific literacy associated with knowledge of scientific phenomena, vocabulary and concepts; Intermediate Scientific Literacy (LTC-2), the second level, referring to the process and thinking skills that are practiced in learners' everyday life; and Advance Scientific Literacy (LTC-3), highest level, referring to the expertise in applying scientific inquiry processes in daily problem solving.

Scientific literacy acquisition in the primary grades poses newer challenging tasks. In primary education (7 - 11 years of age), learners who are passing through the concrete operational stage bear tremendous development potentials (Santrock, 2017) which can be further enhanced by utilizing varied fun-laden materials. In the learning of science, a handful of studies conclude that integrating visual arts aids children's progress and growth both mentally and physically (Dhanapal, Kanapathy, \& Mastan, 2014). For instance, the use of comics was acclaimed as one of the effective and exciting ways to communicate science to learners (Farinella, 2018; Hosler \& Boomer, 2011; Kim, Chung, Jang, \& Chung, 2017; Tatalovic, 2009) and information-based comics were found to educate, inform or teach readers something by using visual elements (Caldwell, 2012). Further, some potential cognitive benefits of comics were charted as follows: (1) visual models make scientific concepts more concrete and accessible; (2) spatial contiguity makes it easier to integrate text and images; and (3) narrative structure could make a scientific material easier to comprehend and claimed that using comics in the classroom improves literacy where pictorial expression of verbal content helped learners interpret words as well as sentences and notice important aspects of a story's setting, tone, and other contextual features (Jee \& Anggoro, 2012).

From the science inquiry-based perspective, comics can improve characters and cognitive achievement of primary school students (Yulianti, Khanafiyah \& Sulistyorini, 2016) and although comics can be a promising tool for science education, potential biases arising from the effects of varied classroom settings and the novelty effect of comics were equally foreseen (Farinella, 2018). One of the pioneers in this area, McCloud (1994, p. 9) defines comics as "juxtaposed pictorial and other images in deliberate sequence, intended to convey information and/or to produce an aesthetic response in the viewer". The features of a comic include the (1) employment of both words and visual elements to communicate; and (2) text organized into sequential units, graphically separated from each other (Caldwell, 2012; Saraceni, 2003).

Presenting scientific information through comics has been studied as an effective tool to transmit scientific literacy that should be adopted in the classroom (Farinella, 2018; Hosler \& Boomer, 2011; Kim et. al., 2017; Tatalovic, 2009; Yulianti et. al., 2016). In addition, Lo Iacono and de Paula (2011) state that 
although the use of comics was proven to be constructive in motivating and engaging learners, they still assume passive roles since they are not involved in the acquisition process and translation of scientific knowledge.

Another study on inquiry-based science comics covered a series of illustrated stories that explored the material science subjects (physics) for fifth grade students. It contained four sub-topics on heat and temperature, namely: (1) the concept of heat and temperature; (2) the concept of heat transfer; (3) heat transfer: conduction; (4) heat transfer: convection and radiation (Yulianti et. al., 2016). Comics in this research embedded practical science tasks in situations of learners' daily and social lives that are represented by the characters. The results reveal that learners were actively encouraged to feel the situation/setting while reading. The series of comics that were developed emphasized visual and textual representations to build the knowledge of science in interesting daily life contexts through dialogue, humorous cartoons, scientific experiment, as well as scientific pictures. The dialogues provide opportunities for the readers to address possible questions, discussion, expert's explanations and interesting conversations. Inquiry sequences are also embedded as the series activity of observing, questioning, exploring, discussing and evaluating as shown on Figure 1.

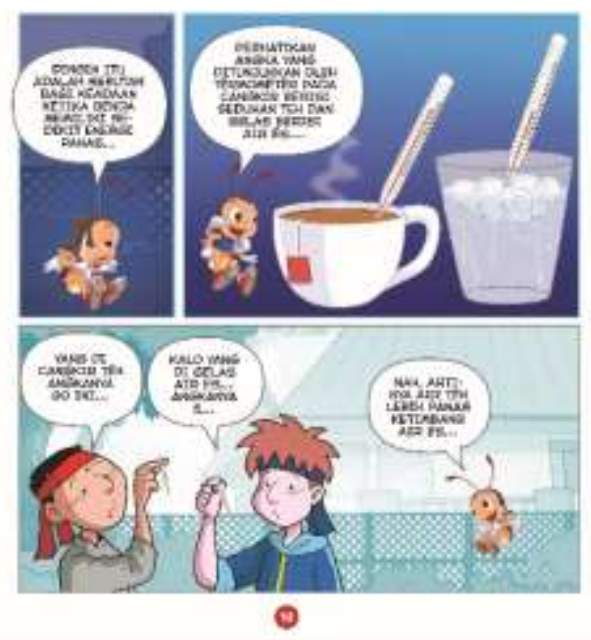

(a)

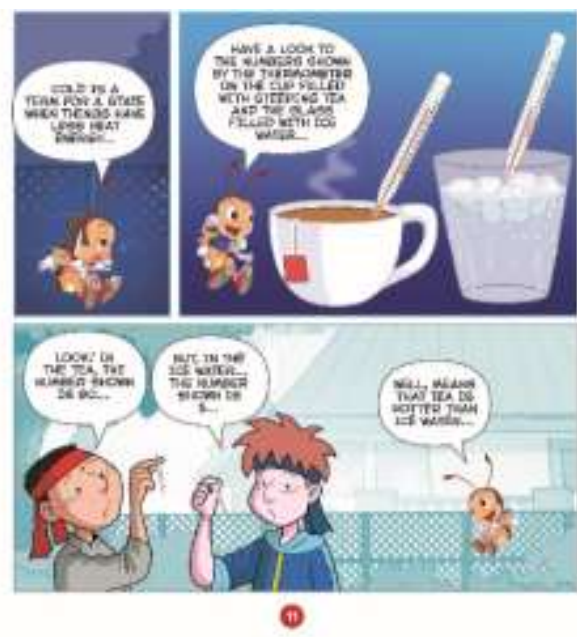

(b)

Figure 1. Scientific setting presented by the characters in the comic (a) Indonesian version (b) English version

Figure 1 shows how the comic stimulates the learners to do an inquiry sequence through the scientific process such as comparing the results of the temperature gauge of different objects by using a thermometer. Learning by inquiry is defined as the activities of students in which they develop the knowledge and understanding of scientific ideas, as well as the understanding of how a scientist studies the natural world (Riga et. al., 2017).

These studies affirm that the benefit of using comics in education and science literacy is not a new concept but exploring how inquiry-based comics as a visual learning medium to foster learners' understanding of natural phenomena and its scientific literacy are still limited. Thus, this research aims to examine whether inquiry-based science comics can significantly increase the scientific literacy skills of primary grade learners and in which level of scientific literacy skills among the primary grade learners will it be projected.

The paper draws attention to the benefits of using inquiry-based science comics in leveraging scientific literacy skills. Based on empirical evidence and valuable insights from the respondents, this research also contributes to the limited literature on the use of instructional inquiry-based science comics in the primary years. 


\section{Research Methodology}

This research employs a quasi-experimental approach, specifically, the pre-test/post-test control group design. Figure 2 describes the structure of the research in brief.

\begin{tabular}{|c|c|c|c|}
\hline Group & $\begin{array}{c}\text { Initial } \\
\text { observation }\end{array}$ & Treatment & $\begin{array}{c}\text { Post } \\
\text { observation }\end{array}$ \\
\hline \multirow[b]{2}{*}{ Experiment } & \multicolumn{3}{|c|}{ Inquiry-based science comic } \\
\hline & Pretest & $\begin{array}{l}\text { Inquiry (Pre, while and post } \\
\text { reading) based learning }\end{array}$ & Posttest \\
\hline \multirow[b]{2}{*}{ Control } & & National-based book & \\
\hline & Pretest & $\begin{array}{l}\text { Inquiry (Pre, while and post } \\
\text { reading) based learning }\end{array}$ & posttest \\
\hline
\end{tabular}

Figure 2. Research Design

The population of this study is fifth grader students of one of the public elementary school in SDN (Sekolah Dasar Negeri/public elementary school) 5 Gunung Putri, Bogor regency, West Java, Indonesia. The population size includes 180 students from five (5) classes. The sampled respondents comprised 72 pupils and were chosen using purposive random sampling. To conform with the regular class size, 36 pupils were non-randomly assigned in the experimental group and the rest (36 students) were placed in the control group. It is to be noted that the school chosen in this study represents the characteristics needed to establish internal validity. Firstly, the school is located between the border of the urban and suburban region which simply denotes better representation of students and student attributes. Secondly, the same school is acclaimed as a public pilot school by the Indonesian government. Thirdly, the intervention inquiry-related activities conformed with the time, schedule and prescribed Grade 5 science curriculum. Lastly, the sessions which were delivered by a qualified science classroom teacher, a model teacher were observed with the presence of 3 inter-raters and were video recorded. Prior to the research, the teacher received a series of interface sessions with the researchers to ensure that the implementation of each instructional activity was understood and how the treatment be implemented.

The inquiry sequences of observing, questioning, exploring, discussing and evaluating were integral features of the inquiry-based comics and were emphasized during class sessions. The materials in the printed comics included the topic on heat and temperature which were divided into four (4) sub-topics, namely: (1) the concept of heat and temperature; (2) the concept of heat transfer; (3) heat transfer: conduction; and (4) heat transfer: convection and radiation. The entire topic was designed to provide opportunities for the learners to build links between scientific concepts and current issues such as climate change through simulation activities, hands-on experiments, manipulative games, among others. In so doing, the learners were triggered to display their insights and skills approximating the desired scientific processes in each and every session introduced.

As an instructional inquiry medium, the comics were critiqued, pre-tested and revised accordingly with the participation of (3) pedagogical content and (2) technical experts. For the duration of six (6) weeks, there were six (6) lessons of intervention for which the comics served both as reading material and a reference guide during the conduct of scientific literacy activity. The comics featured science knowledge and skills in three (3) levels: LTC-1: understanding the scientific concepts of heat and its transfer; LTC-2: applying the basic knowledge of heat and its transfer in daily life; and LTC 3-skills: demonstrating hands-on inquiry activity about heat and its transfer. 
The construction of the pre-test and the post-test approximated the three (3) levels of science literacy. It composed of 20 items of multiple choice including 6 items of LTC-1, 7 items of LTC-2 and 7 items of LTC3 . The reliability of the instrument (reliability of estimate: 0,83 ) was secured using the Rasch model. All of the items were fit based on criteria of $\mathrm{P}<0,05 ; 0,5<\mathrm{MNSQ}<1,5$. The first and the last lessons were assigned to the implementation of pre-test and post-test. A focus group discussion was conducted separately with the teacher and the pupils capped the completion of the study. The means of the gain scores of experiment and control group both used descriptive and hypothesis t-test statistics. Improvements in the learners' scientific literacy skills were also qualitatively triangulated through a series of obtrusive learning observations, learners' experiments and related artefacts, and post-mortem group discussions.

\section{Results and Discussion}

The research was designed to investigate the effect of inquiry-based science comics on primary learners' scientific literacy skills. The t-test of gained score for experimental and control group was used. The results indicate that the group that used inquiry-based science comics made significant improvements in their scientific literacy through reading and the assigned learning process (sig $0,007<<0,05$ ).

Table 1: Test of Between-Subjects Effects

\begin{tabular}{|c|c|c|c|c|c|}
\hline Source & $\begin{array}{c}\text { Type III Sum of } \\
\text { Squares }\end{array}$ & df & Mean Square & F & sig \\
\hline Corrected Model & $0.364 \mathrm{a}$ & 1 & 0.364 & 7.606 & 0.007 \\
\hline Intercept & 0.460 & 1 & 0.460 & 9.605 & 0.003 \\
\hline Kelas & 0.364 & 1 & 0.364 & 7.606 & 0.007 \\
\hline Error & 3.208 & 67 & 0.48 & & \\
\hline Total & 4.070 & 69 & & & \\
\hline Corrected Total & 3.572 & 68 & & & \\
\hline
\end{tabular}

Dependent Variable: Gain_Total

a. $\quad$ R Squared $=0.102$ (adjusted R Squared $=0.0896$ )

The use of inquiry-based science comics benefited the primary learners in the formal (classroom) context. In order to examine in which level of scientific literacy skills among the primary grade learners is projected by using Inquiry-based science comics, the score of the pre-test and post-test means was compared descriptively. This shows that there was a significant increase in overall scientific literacy. Table 1 shows the descriptive results in brief.

Table 1. Gain Scores Across Level of Scientific Literacy

\begin{tabular}{|c|c|c|c|c|}
\hline $\begin{array}{c}\text { Gain scores of Scientific } \\
\text { Literacy Skills }\end{array}$ & LTC1 & LTC2 & LTC3 & $\begin{array}{c}\text { LTC } \\
\text { (Overall) }\end{array}$ \\
\hline Experiment Group & 0.20 & 0.15 & 0.10 & 0.15 \\
\hline Control Group & -0.13 & -0.06 & 0.00 & 0.01 \\
\hline
\end{tabular}

The highest gained score (0.20) shows the largest improvement in learners' scientific literacy skills in LTC-1 (Scientific concept and phenomena). In contrast, no marked improvement is observed in the control group. These results indicate that not all levels of scientific literacy are strengthened; only the basic level (LTC-1 and LTC-2) has improved.

The use of inquiry-based science comics as literacy materials proves to be an effective instructional activity. Tatalovic (2009) states that comics can be used for communicating science to the public; it lies in 
the fact that the learners can easily relate to the setting and experience demonstrated. The learners' scientific literacy skills were strengthened. The increase in scores occurs in the first (LTC-1) and second (LTC-2) levels of scientific literacy. Basic scientific literacy which only covers the development of knowledge and understanding phenomena and concept and uses those in everyday life problem solving can be strengthened using the media in a pictorial expression of verbal content. Lin and Lin (2016) argued that presenting materials through multiple representations (i.e. verbal and visual elements) contribute to constructing a mental model and can promote learners' concept learning by providing appropriate scaffolding to fill learners' cognitive gaps due to deficiencies in their prior knowledge.

Affeldt, Meinhart and Eilks (2018) suggest that comics have the potential to increase learner motivation and personal engagement when dealing with scientific issues. This was confirmed in the post-mortem group interview, when a learner said that the inquiry-based science comic motivated him to read about scientific concepts. Simply, the comics provided a more entertaining atmosphere while learners did the reading activity. The curiosity of learners was also nurtured due to the content of the comics. In one of the lessons on heat diffusion, the experimental class displayed insights beyond scientific information such as the relationship between heat transfer and climate change in daily life. Here, the learners were encouraged to seek out more information from various resources and were motivated to conduct individual and group guided experiments.

There was an excess effect for learners who read the inquiry-based science comics. Their abilities in diagraming, data charting and drawing conclusions were honed gradually. During class interactions, observation results revealed that some learners were engaged in situated thinking processes using the comics with inquiry sequences such as asking scientifically oriented questions, using evidence-based inputs, formulating alternative explanations based on evidence and connecting it to scientific knowledge, while some of them simply explained their observations during class experiments. This indicates that giving out directions with inquiry sequence, one of the features of the comics, must have reinforced the display of cognitive skills.

Although the basic scientific literacy was facilitated in the story of comics and directed by inquiry sequence, the use of comics has certain limitations in improving the highest scientific literacy (LTC-3) due to (1) the lack of exposure to activities such as hands-on experiments and projects, and (2) the structured class time (system mandated) and the study duration (4 weeks) which are all crucial requirements to achieve LTC3.

\section{Conclusion}

The use of inquiry-based science comics increased the opportunity for learners to receive access to scientific reading, to think critically about scientific phenomena, and to discuss scientific concepts. This is to say that the increase in the scientific literacy skills between the experimental and control groups reinforced the cognitive and physical benefits of using inquiry-based science comics. The comics are limited to increasing the highest scientific literacy skills. Due to the limitations of the research, further research is needed to enhance more activities and projects to give them extra exposure on practicing their scientific literacy skills. Essentially, the combined exposure of learners to visual learning comics and hands-on guided experiments enhances their awareness of daily science issues and basic problem-solving initiatives. These results can be used as a base of literature to develop inquiry-based science learning reading materials.

\section{References}

Affeldt, F., Meinhart, D., \& Eilks, I. (2018). The use of comics in experimental instructions in a non-formal chemistry learning context. International Journal of Education in Mathematics Science and Technology, 6(1), 93-104. https://doi.org/10.18404/ijemst.380620 
Caldwell, J. (2012, October). Information comics: An overview. In 2012 IEEE International Professional Communication Conference (pp. 1-7). IEEE.https://doi.org/10.1109/IPCC.2012.6408645

Dhanapal, S., Kanapathy, R., \& Mastan, J. (2014, December). A study to understand the role of visual arts in the teaching and learning of science. In Asia-Pacific Forum on Science Learning and Teaching (Vol. 15, No. 2, pp. 1-25). The Education University of Hong Kong, Department of Science and Environmental Studies. https://www.eduhk.hk/apfslt/download/v15_issue2_files/dhanapal.pdf

Farinella, M. (2018). The potential of comics in science communication. Journal of science communication, 17(1), Y01. https://doi.org/10.22323/2.17010401

Hosler, J., \& Boomer, K. B. (2011). Are comic books an effective way to engage nonmajors in learning and appreciating science?. CBE-Life Sciences Education, 10(3), 309-317.https://doi.org/10.1187/cbe.10-07-0090

Jee, B. D., \& Anggoro, F. K. (2012). Comic cognition: exploring the potential cognitive impacts of science comics. Journal of Cognitive Education and Psychology, 11(2), 196-208.https://doi.org/10.1891/1945-8959.11.2.196

Kim, J., Chung, M. S., Jang, H. G., \& Chung, B. S. (2017). The use of educational comics in learning anatomy among multiple student groups. Anatomical sciences education, 10(1), 79-86. https://doi.org/10.1002/ase.1619

Lin, S. F., \& Lin, H. S. (2016). Learning nanotechnology with texts and comics: The impacts on students of different achievement levels. International Journal of Science Education, 38(8), 13731391.https://doi.org/10.1080/09500693.2016.1191089

Lo Iacono, G., \& de Paula, A. S. (2011). A pilot project to encourage scientific debate in schools. Comics written and peer reviewed by young learners. Journal of Science Communication, 10(3), A04. https://jcom.sissa.it/archive/10/03/Jcom1003(2011)A04

McCloud, S. (1994). Understanding Comics: The Invisible Art. New York: HarperCollins Publisher, Inc.

National Research Council. (1996). National science education standards. National Academies Press.

Norris, S. P., \& Phillips, L. M. (2003). How literacy in its fundamental sense is central to scientific literacy. Science education, 87(2), 224-240.https://doi.org/10.1002/sce.10066

OECD. (2000). The PISA 2000 Assessment of Reading, Mathematical and Scientific Literacy. $2000,12-19$. https://doi.org/http://www.oecd.org/edu/school/programmeforinternationalstudentassessmentpisa/33692793.pdf

OECD. (2015). PISA 2015 Item Submission Guidelines: Scientific Literacy. Paris: ETS.

Riga, F., Winterbottom, M., Harris, E., \& Newby, L. (2017). Inquiry-based science education. In Science education (pp. 247-261). Brill Sense. https://brill.com/downloadpdf/book/edcoll/9789463007498/BP000020.pdf

Santrock, J. W. (2017). LIFE-SPAN Development (13th ed.). In McGraw-Hill.

Saraceni, M. (2003). The Language of Comics. In The Art of Comics: A Philosophical Approach. https://doi.org/10.1002/9781444354843.ch7

Tatalovic, M. (2009). Science comics as tools for science education and communication: a brief, exploratory study. Journal of Science Communication, 8(4), A02.https://doi.org/10.22323/2.08040202

Wallace, C. S. (2004). Framing new research in science literacy and language use: Authenticity, multiple discourses, and the "Third Space". Science Education, 88(6), 901-914.https://doi.org/10.1002/sce.20024

Yulianti, D., Khanafiyah, S., \& Sulistyorini, S. (2016). Inquiry-based science comic physics series integrated with character education. Jurnal Pendidikan IPA Indonesia, 5(1), 38-44. https://doi.org/10.15294/jpii.v5i1.5787

Yuliati, L., Yogismawati, F., \& Nisa, I. K. (2018, September). Building Scientific Literacy and Concept Achievement of Physics through Inquiry-Based Learning for STEM Education. In Journal of Physics: Conference Series (Vol. 1097, No. 1, p. 012022). IOP Publishing.doi:10.1088/1742-6596/1097/1/012022 